\title{
A!
}

This is an electronic reprint of the original article.

This reprint may differ from the original in pagination and typographic detail.

Le, Nguyen Duc; Trogen, Mikaela; Ma, Yibo; Varley, Russell J.; Hummel, Michael; Byrne, Nolene

Understanding the influence of key parameters on the stabilisation of cellulose-lignin composite fibres

Published in:

Cellulose

DOI:

$10.1007 / \mathrm{s} 10570-020-03583-y$

Published: 01/01/2021

Document Version

Peer reviewed version

Please cite the original version:

Le, N. D., Trogen, M., Ma, Y., Varley, R. J., Hummel, M., \& Byrne, N. (2021). Understanding the influence of key parameters on the stabilisation of cellulose-lignin composite fibres. Cellulose, 28(2), 911-919.

https://doi.org/10.1007/s10570-020-03583-y

This material is protected by copyright and other intellectual property rights, and duplication or sale of all or part of any of the repository collections is not permitted, except that material may be duplicated by you for your research use or educational purposes in electronic or print form. You must obtain permission for any other use. Electronic or print copies may not be offered, whether for sale or otherwise to anyone who is not an authorised user. 


\section{Understanding the influence of key parameters on the stabilisation of cellulose-lignin composite fibres.}

3 Nguyen-Duc Le ${ }^{\mathrm{a}}$, Mikaela Trogen ${ }^{\mathrm{b}}$, Yibo Ma ${ }^{\mathrm{b}}$, Russell J. Varley ${ }^{\mathrm{a}}$, Michael Hummel ${ }^{\mathrm{b}}$ and Nolene Byrne ${ }^{\mathrm{a}}$

4 a. Institute for Frontier Materials, Deakin University, Australia

5 b. Department of Bioproducts and Biosystems, Aalto University, Finland.

6

Abstract: The high cost of carbon fibre continues to limit its use in industries like automotive, construction and energy. Since the cost is closely linked to the precursor, considerable research has focussed on the use of low-cost alternatives. A promising candidate is a composite fibre consisting of blended cellulose and lignin, which has the added benefit of being derived from sustainable resources. The benefits of blending cellulose and lignin reduce some of the negative aspects of converting single component cellulose and lignin fibres to carbon fibre, although the production from such a blend, remains largely underdeveloped. In this study, the effects of stabilisation temperature and the stabilisation process of the blended fibres are explored. Moreover, the viscoelastic properties of the cellulose-lignin fibre are investigated by DMA for the first time. Finally, the cause of fusion in the stabilisation is adressed and solved by applying a spin finish.

Keywords: Bio-polymer, Cellulose-lignin composite fibres, low-cost carbon fibres, DMA, stabilisation, viscoelastic, bio-resources.

\section{Introduction:}

The high strength to weight ratio of carbon fibre $(\mathrm{CF})$ makes it an ideal material for many applications in the aerospace, military, construction, and sports manufacturing industries. For this reason it is already being utilised in many high-performance applications and it is anticipated that the market share of CF composites will double over the next ten years (Bohner et al. 2015). However, its high cost continues to limit applications in industries that rely on high volume manufacturing, such as the automotive industry. A major reason for this, pointed out by Baker et al. (Baker et al. 2012) is that the most commonly used fossil fuel derived precursor, polyacrylonitrile (PAN) accounts for about $50 \%$ of the cost of $\mathrm{CF}$, placing a limit on potential cost reductions (Frank et al. 2014; Choi et al. 2019).

Due to the current limitations associated with PAN and the depletion of oil, the search for new bio-based precursors for CF production is generating considerable interest. Alternative precursors such as lignin and cellulose have been extensively investigated as have blends of polymers (Frank et al. 2012; Ogale et al. 2016). Although these approaches are interesting, 
they suffers from some technical problems, such as the slow stabilisation rate of lignin (Sudo et al. 1993; Kadla et al. 2002; Zhang et al. 2015; Fang et al. 2017) and its poor fibre strength (20-35 MPa) (Uraki et al. 1995) making it difficult to use in a continuous production line. For cellulose, despite being able to be spun into high quality precursor filaments, it has a low carbon yield and high production costs due to the need for hot stretching graphitization at very high temperature $\left(2000{ }^{\circ} \mathrm{C}-3000{ }^{\circ} \mathrm{C}\right.$ ) (Morgan 2005; Frank et al. 2014). Composite fibres containing both lignin and cellulose therefore have been proposed as a solution to this problem by achieving a balanced product. Ma et al. produced high strength cellulose-lignin fibres by dry-jet wet spinning using an ionic liquid as a solvent (Ma et al. 2015). The resultant fibres had high crystallinity and orientation in comparison to lignin precursors, a prerequisite for high-performance CF. Moreover, the combination of lignin and cellulose improved mechanical strength in comparison to pure lignin. As a result, the composite fibres are now potential candidates for continuous CF production, rather than the less economical bath conversion process. As expected, the composite fibres had a higher carbon yield than traditional cellulose precursors, which is favourable for improved CF production (Olsson et al. 2017; Vincent et al. 2018; Bengtsson et al. 2019). Olsson et al. spun composite fibres from $70 \%$ kraft lignin and 30\% cellulose as CF precursors using ionic liquid-based air gap spinning (Olsson et al. 2017). The obtained precursors were stabilised in air up to $250^{\circ} \mathrm{C}$ with a slow heating rate $\left(0.02^{\circ} \mathrm{C} / \mathrm{min}\right.$ to $\left.1^{\circ} \mathrm{C} / \mathrm{min}\right)$ before being carbonised at $1000^{\circ} \mathrm{C}$ in $\mathrm{N}_{2}$. The $\mathrm{CFs}$ mechanical properties were reported to be $780 \mathrm{MPa}$ for tensile strength and $68 \mathrm{GPa}$ for tensile modulus. However, no further details about the stabilisation mechanism or mechanical properties during stabilisation of the composite fibres were provided. Lehmann et al. also patented a method for wet or air gap-spinning of cellulose-lignin composite fibres and their carbonisation, but again, no details were given about the change in properties of the precursor during the heat treatment process. Byrne et al. conducted the stabilisation of a lignin-cellulose composite fibre produced via the Ioncell process (Byrne et al. 2018) and found that the addition of cellulose significantly decreases the stabilisation time of lignin. To date, however, the evolution of composite fibres during stabilisation has not been fully explored. Unfortunately, the properties of the cellulose-lignin fibres converted to carbon fibre remain well below the requirements for most industry applications (Huang 2009; Frank et al. 2014; Ogale et al. 2016), necessitating further studies to understand their stabilisation prior to carbonisation.

In this paper, the effect of temperature on the stabilisation rate of the composite fibres was investigated using FTIR to determine the stabilisation conversion over time. The influence of the stabilisation temperature and lignin content on carbon yield, morphology and viscoelasticity of the fully stabilised fibres were also determined. In addition, the viscoelasticity and thermal properties of the precursor with different lignin content were also studied. 


\subsection{Materials:}

Precursor fibres were dry-jet wet spun at Aalto University, Finland according to a method described elsewhere (Ma et al. 2015). Pre-hydrolysed kraft birch pulp (Stora Enso Enocell mill, Finland) and organosolv beech lignin (Fraunhofer CBP, Leuna, Germany) were used as raw materials. The raw materials were dissolved in an ionic liquid (1,5diazabicyclo[4.3.0]non-5-enium acetate [DBNH]OAc) to form a dope in a polymeric concentration range from $15 \mathrm{wt} . \%$ to $17 \mathrm{wt} . \%$. The ionic liquid was prepared by the reaction between 1,5-diazabicyclo[4.3.0]non-5-ene (DBN) (Fluorochem, UK) and acetic acid (glacial, $100 \%$, Merck, Germany) (Trogen et al. 2021). The dope was heated to $71 \pm 3^{\circ} \mathrm{C}$ before extruding through a 400-hole spinneret. The extruded dope passed through a $1 \mathrm{~cm}$ air gap before it was coagulated in a cold-water bath $\left(9 \pm 2^{\circ} \mathrm{C}\right)$. The resultant cellulose-lignin filaments were then passed through successive aqueous washing baths to remove any remaining residual ionic liquid. The draw ratio of the filaments is 6 and was kept the same by controlling the ratio between the take-up velocity and the extrusion velocity. Three compositions of fibre used in this experiment are 100-0 (100 wt \% cellulose), 70-30 (70 wt \% cellulose - $30 \mathrm{wt} \%$ lignin), 5050 (50 wt \% cellulose - $50 \mathrm{wt} \%$ lignin). Prior to use, fibre samples were stored at all time in a desiccator to prevent moisture absorption.

2.2 Preparation of stabilised fibres:

Precursors were hung on a stainless-steel rack while applying a tension of $15 \mathrm{~N}$. The stabilisation was conducted in air using a Binder FD53 oven at different temperatures $\left(240^{\circ} \mathrm{C}\right.$, $\left.260^{\circ} \mathrm{C}, 280^{\circ} \mathrm{C}\right)$. Samples were placed directly into the oven when the temperature had stabilised at the set temperature. (diluted in water with ratio 1:6). After immersed in the spin finish, the fibre was swept to remove the excess agent before drying at $80^{\circ} \mathrm{C}$ for $24 \mathrm{~h}$. The stabilisation was conducted in the air with same manner as other samples at $280^{\circ} \mathrm{C}$ for $1 \mathrm{~h}$.

\subsection{Preparation of stabilised fibres treated with finishing agents:}

Precursors (70-30) were immersed in a commercial spin finish agent (Delion AUS-002)

\subsection{Fourier-transform infrared spectroscopy (FTIR):}

FTIR analysis of stabilised tows was performed on Bruker Vertex FTIR in the attenuated total reflection mode (ATR mode). The scan ranges from 650 to $4000 \mathrm{~cm}^{-1}$, at the scan resolution of $2 \mathrm{~cm}^{-1}$ and scan time of 32 scans.

\subsection{Dynamic Mechanical Analysis (DMA):}


Individual filaments were separated from the tow to measure the viscoelastic tensile properties of the fibre. The test was performed using a TA Instruments dynamic mechanical analyser (TA Q800) in the tensile mode using a frequency sweep ranging from $0.1-200 \mathrm{~Hz}$ at $30^{\circ} \mathrm{C}$ or a temperature sweep using a heating rate of $2{ }^{\circ} \mathrm{C} / \mathrm{min}$ from $50^{\circ} \mathrm{C}$ to $250^{\circ} \mathrm{C}$ at $1 \mathrm{~Hz}$. The slow heating rate allows the evaporation of moisture in the fibres. The strain was kept constant at $0.1 \%$ and pretension of $0.5 \mathrm{cN}$ was applied. Each measurement is an average of three samples with a length of $15 \mathrm{~mm}$. The linear mass density of a filament was determined by dividing the linear mass density of the whole tow by the number of filaments in a tow.

\subsubsection{Tow measurements:}

DMA measurements of an entire tow were performed similarly to the single filament measurements, using lengths of $15 \mathrm{~mm}$ and reporting the results as an average of 3 replicates. Analysis was performed using a temperature ramp from $30-250{ }^{\circ} \mathrm{C}$ at a rate of $2{ }^{\circ} \mathrm{C} / \mathrm{min}$ and a frequency of $1 \mathrm{~Hz}$. The strain was kept constant at $0.1 \%$ and a pretension of $10 \mathrm{cN}$ was applied. The linear mass density of the whole tow was determined by weighing a defined length of a tow by an analytical balance (Toledo MS105DU).

$\mathrm{kV}$ of voltage. Cross sectional images were obtained from the fracture surface of the fibres after immersion in liquid nitrogen until frozen, then snapped apart. Before observation, all samples were sputter-coated with gold. The fibre diameter was averaged from results of the cross-section of 10 filaments.

\subsection{Scanning electron microscope (SEM):}

The morphology of the obtained samples was observed with a Zeiss Supra 55VP with 3

\subsection{Thermal gravimetric analysis (TGA):}

A TA Instruments Q50 Thermogravimetric Analyser instrument was used to determine weight loss during stabilisation. Approximately 5-6 $\mathrm{mg}$ of the sample was heated from room temperature to $600{ }^{\circ} \mathrm{C}$ with a heating rate of $20{ }^{\circ} \mathrm{C} / \mathrm{min}$ in a non-oxidative $\left(\mathrm{N}_{2}\right)$ atmosphere.

\section{Results and discussion:}

\subsection{Stabilisation yield as a function of lignin content and temperature}

Stabilisation temperature plays an important role in the overall production of carbon fibres because it greatly affects the rate and yield, which ultimately determines properties and cost. To shed further light on how the stabilisation temperature affects the cellulose-lignin composite fibres, different cellulose lignin-containing composite fibres (70-30 and 50-50 wt $\%$ ) were stabilised at different temperatures $\left(240^{\circ} \mathrm{C}, 260^{\circ} \mathrm{C}\right.$, and $\left.280^{\circ} \mathrm{C}\right)$. Thus a stabilisation yield was calculated from the ratio of the initial sample mass and the mass after complete stabilisation. The results of these tests reveal that higher stabilisation temperatures result in 
150 lower stabilisation yields (Figure 1a). This complements other findings which show that higher 151 heating rates decrease stabilisation yield (Ford and Mitchell 1963; Brunner and Roberts 1980). 152 Another interesting point is that the stabilisation yield of 70-30 is greater than 50-50 at these 153 temperatures, which is contrary to previous findings in this field (Ma et al. 2015). These 154 contrasting results can be understood however through closer inspection of the TGA results as 155 follows. Up to $350^{\circ} \mathrm{C}$, the weight loss of 50-50 is more than 70-30, a reflection of the greater 156 susceptibility of lignin to degradation and its propensity to form volatile compounds $\left(200^{\circ} \mathrm{C}\right.$ 157 (Bajpai 2017), 240 C (Tang and Bacon 1964), respectively). As a phenolic containing polymer, 158 chain scission within lignin chains can readily occur and release radicals which can either 159 propagate or terminate to form either char layer or volatile gases depending upon the reaction 160 mechanism. This is in contrast to cellulose which has greater thermal stability, but degrades 161 faster than lignin producing a lower carbon yield (Trogen et al. 2021). Above $350^{\circ} \mathrm{C}$, however, 162 the weight loss of 50-50 becomes lower than 70-30 as the lignin is able to form a more stable char layer, due to its largely aromatic crosslinked structure created by degradation of lignin 164 (Kawamoto 2017; Ghysels et al. 2019). Above $350^{\circ} \mathrm{C}$, however, the weight loss of 50-50 165 becomes lower than 70-30 as the lignin is able to form a more stable char layer, due to its 166 largely aromatic crosslinked structure created by degradation of lignin (Kawamoto 2017; 167 Ghysels et al. 2019).

a)

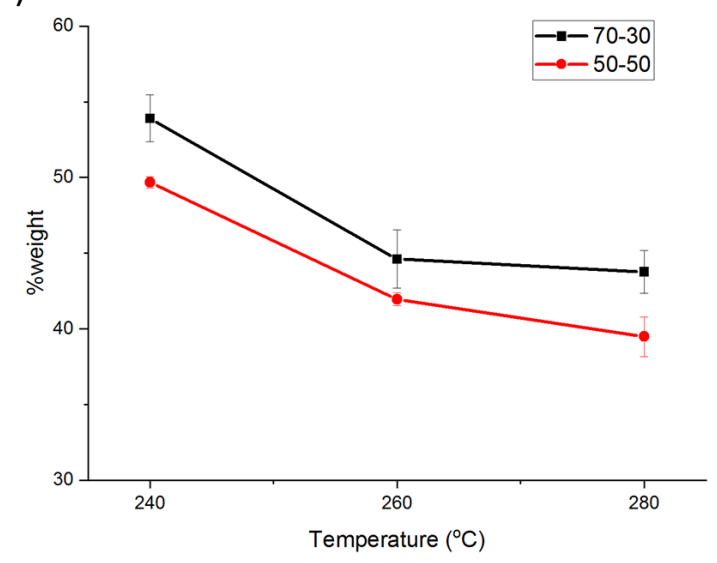

b)

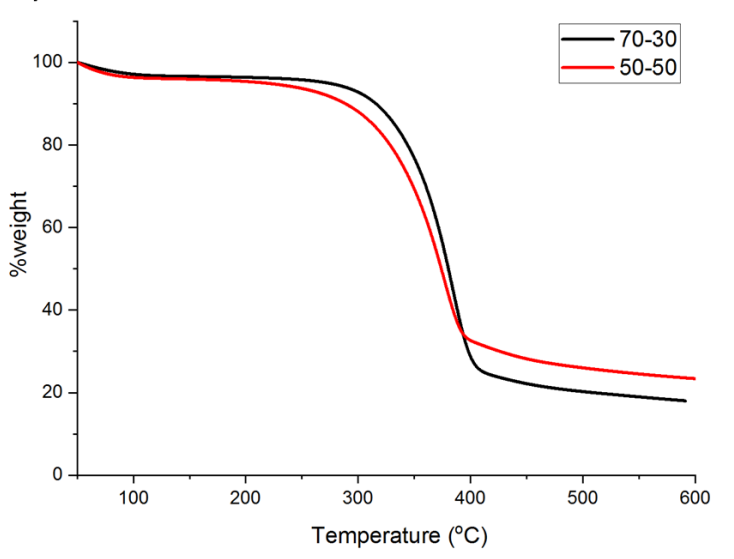

Figure 1: a) Stabilisation yields as function of lignin content and temperature and b) TGA for unstabilised cellulose-lignin composite fibres.

\subsection{Stabilisation rate as a function of stabilisation temperature}

In addition to the stabilisation yield, the stabilisation rate also depends on the 172 stabilisation temperature and lignin content. To explore this, a relative stabilisation conversion

173 index determined by FTIR was calculated from the ratio of the $\mathrm{C}=\mathrm{O}$ peak at $1720 \mathrm{~cm}^{-1}$ and the $174 \mathrm{C}-\mathrm{H}$ peak at $1435 \mathrm{~cm}^{-1}$ (Byrne et al. 2018). The $\mathrm{C}=\mathrm{O}$ peak accounts for the oxidation process 175 of cellulose and lignin, which increases during stabilisation and stabilises when the oxidation 
process is complete. The $\mathrm{C}-\mathrm{H}$ peak is used as an internal standard because it is assumed to be unaffected by the oxidation process.

Figure 2 shows that the 70-30 composite fibre stabilised faster than 50-50 did reflecting the slower rate of stabilisation of lignin compared with cellulose. However, since pure lignin fibres, can require up to $40 \mathrm{~h}$ to reach a stabilised state (Zhang et al. 2015), these results for the both the 70-30 and 50-50 composite fibres demonstrate a significant enhancement in rate of stabilisation. Indeed, the 50-50 cellulose lignin blend shown here is able to fully stabilise after only $2 \mathrm{hrs}$ at $280^{\circ} \mathrm{C}$. Therefore, since it is known that lignin has a higher carbon yield (Uraki et al. 1995; Kubo and Kadla 2004; Zhang et al. 2015), the enhancement in stabilisation due to the addition of cellulose in these blends provides significant potential to reduce the overall costs of carbon fibre production (Ma et al. 2015; Olsson et al. 2017), assuming satisfactory mechanical properties can be achieved.

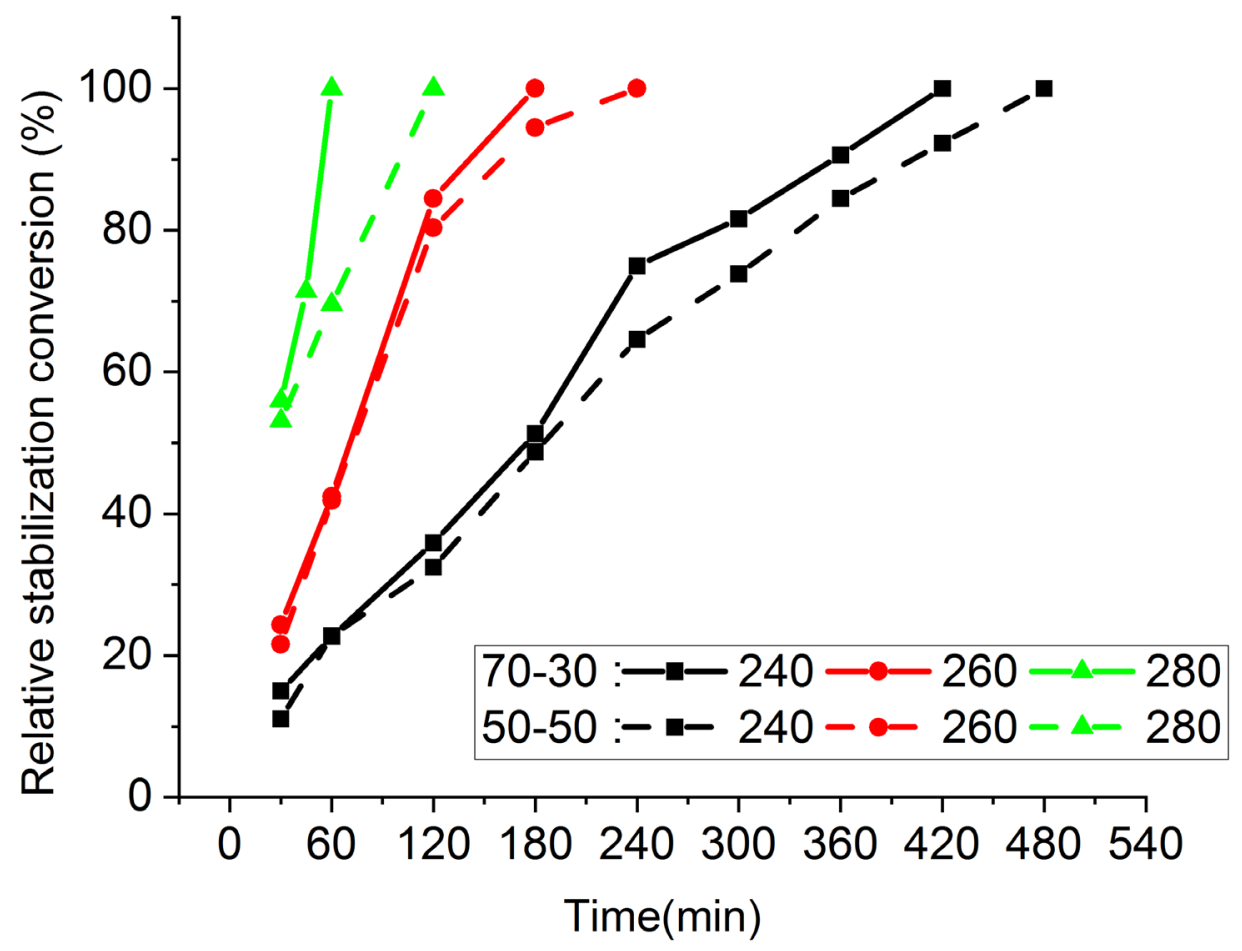

Figure 2 Stabilisation time as a function of temperature and lignin content

\subsection{Viscoelastic properties of precursor fibres}

The viscoelastic tensile properties of lignin-cellulose composite fibres were studied using DMA and compared with 100\% cellulose fibres as reference. As shown in Figure 3a, both the storage modulus and loss modulus of 100-0 are higher than 70-30 and 50-50 indicative of the deleterious impact of lignin on the viscoelastic properties of the composite fibres (Ma et al. 2015; Bajpai 2017). 
The temperature sweep diagram shows the mechanical properties as a function of 202 temperature (Figure $3 \mathrm{~b}$ ). The Tg calculated from the onset of the storage modulus of ioncell

a)

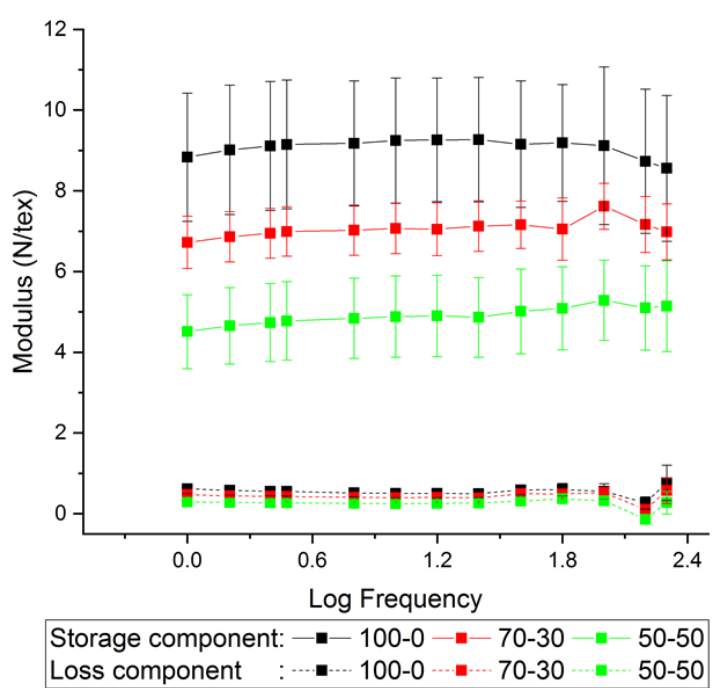

b)

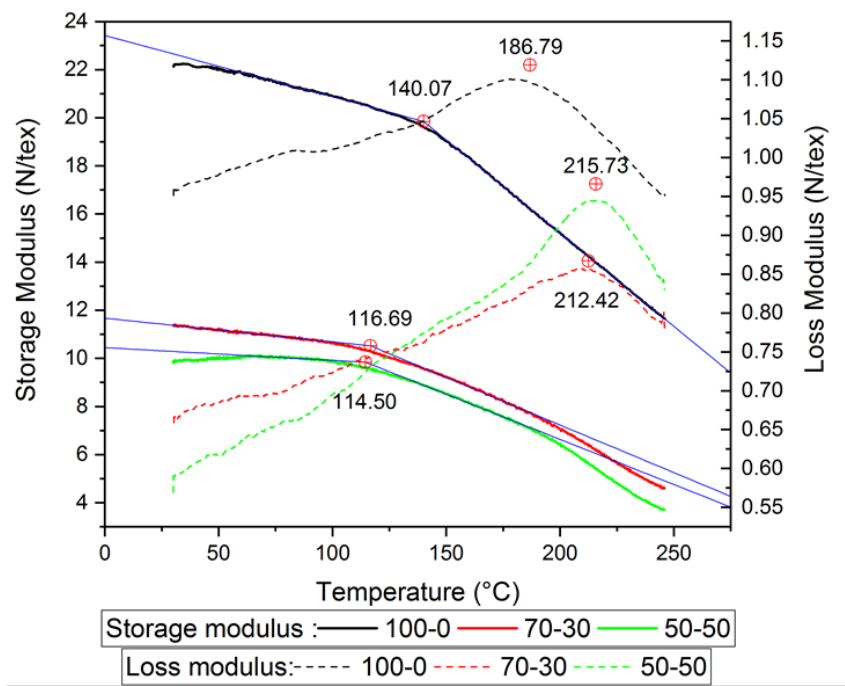

Figure 3: DMA for precursor fibres at a) frequency sweep b) temperature sweep

fibre is $140^{\circ} \mathrm{C}$, which matches previous findings for regenerated cellulose fibres (Jiang et al. 2011). With the addition of lignin, the Tg for the $70-30$ fibre was found to be $117.0^{\circ} \mathrm{C}$, while the $\mathrm{Tg}$ for the $50-50$ fibre was $114.5^{\circ} \mathrm{C}$. The $\mathrm{Tg}$, therefore, decreased with increasing lignin content, reflecting the lower thermal resistance of lignin compared with cellulose. The Tg calculated from the loss modulus peak, however, shows a reverse trend. The loss modulus reflects the ability of a material to dissipate energy through molecular motion. In this case, the high levels of crystallinity in the cellulose accelerate energy dissipation. The addition of lignin, an amorphous polymer, decreases the crystallinity of regenerated fibres (Ma et al. 2015; Boukir et al. 2019; Mikkilä et al. 2020), reducing energy dissipation, leading to an increase in loss modulus (De Nardo and Farè 2017; Shrivastava 2018). The impact of residual IL on the dynamic mechanical properties of the composite fibre in this work is considered to be negligible due to the high efficient nature of the washing process. Washing efficiency is diffusion driven, so the egress of absorbed IL would be inhibited for higher fibre diameters. Since our fibres are smaller, compared to those of Jiang et al, who reported $0.15 \%$ residual IL after washing, residual IL in our fibres would there be significantly lower, and therefore any resultant plasticisation of $\mathrm{Tg}$ also extremely low.

\subsection{Viscoelastic properties of stabilised fibres}

The resulting fibres after stabilisation are weak and partially fused making it difficult to characterise the viscoelastic properties. An alternative approach, however, is to characterise the fibre tows. A comparison between stabilised tows with precursor single fibres (70-30) was made and shown in Figure 4 to see the influence of sample forms with the Tg value. 


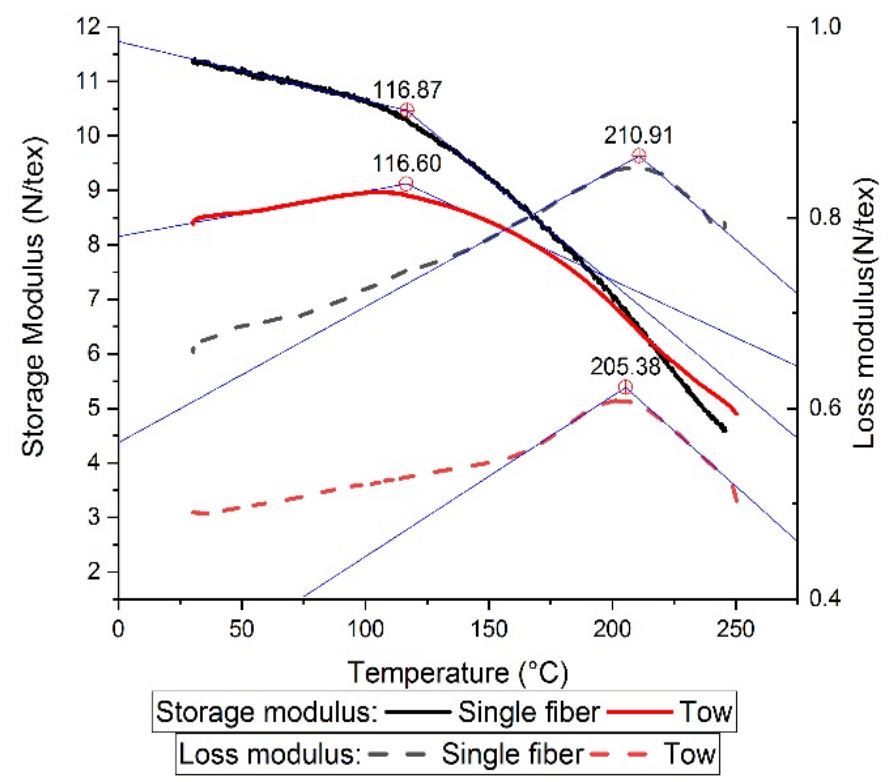

Figure 4: Comparison between single fibres and tow for the 70-30 composite fibre

Despite the different forms, the Tg determined from the tow measurement matches with the $\mathrm{Tg}$ value from the single fibre measurement. Therefore, the effect of temperature on the material can be seen to be independent of fibre form. Subsequently, the fibres (70-30) stabilised at different temperatures were measured over a wide temperature range and are shown in Figure 5a. The storage and loss moduli illustrate the transformation from a pre-cursor displaying a Tg, to stabilised fibres with no observable Tg regardless of temperature (no noticeable change of slope for neither storage modulus nor loss modulus), somewhat validating the completion of stabilisation. There are several different methods to quantify the extent of stabilisation, depending on the precursor being studied. DSC is commonly used for PAN but is not as suitable for highly crosslinked samples such as softwood lignin (Kubo and Kadla 2005; Brodin et al. 2012; Zhang et al. 2015). Similar to softwood lignin, hardwood lignin also has high amounts of cross-linking which make the Tg transition very difficult to observe in the DSC (Lu et al. 2016; Hosseinaei et al. 2017). DMA generally has a higher sensitivity towards Tg than DSC since it directly measures the viscoelastic properties (Lobo and Bonilla 2003; Torregrosa and Diez 2015). Hence, DMA can be an alternative approach to measure the Tg of samples and control the stabilisation process. Indeed, DMA shows that with increasing stabilisation, the $\mathrm{Tg}$ transition diminishes and the storage modulus becomes increasingly stable. This likely reflects a transition to a highly crosslinked network, similar to the transition from a thermoplastic to a thermoset (Cho et al. 2018).

The 50-50 precursor and fully stabilised fibres at $280^{\circ} \mathrm{C}$ were also measured and compared against the 70-30 composite fibres in Figure 5b. Similar behaviour is observed in respect to stabilisation, illustrating a clear Tg transition in the loss and storage moduli spectra for the precursor, which also disappears with increasing stabilisation. The important point to 
note from these results are that increasing lignin content in the 50-50 fibre, significantly reduces or plasticises the loss and storage moduli of the precursor supporting previous reports. After stabilisation at $280{ }^{\circ} \mathrm{C}$ however, the loss modulus also reduces with increasing lignin content, but interestingly the storage moduli are similar regardless of composition. This suggests that the more highly aromatic structure lignin (Byrne et al. 2018) may play a dominant role in determining stiffness (as measured by storage modulus) in the final fibre, while the cellulose likely dominates the ductility (as measured by loss modulus here) of the fibre.

a)

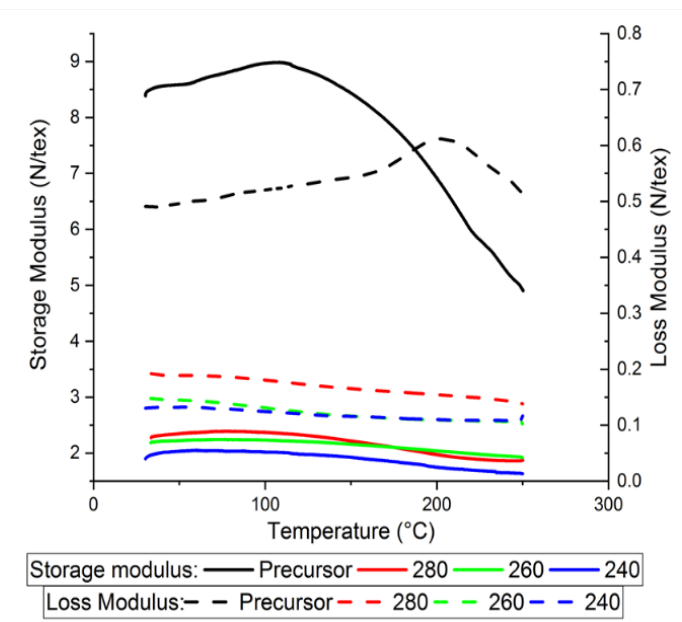

b)

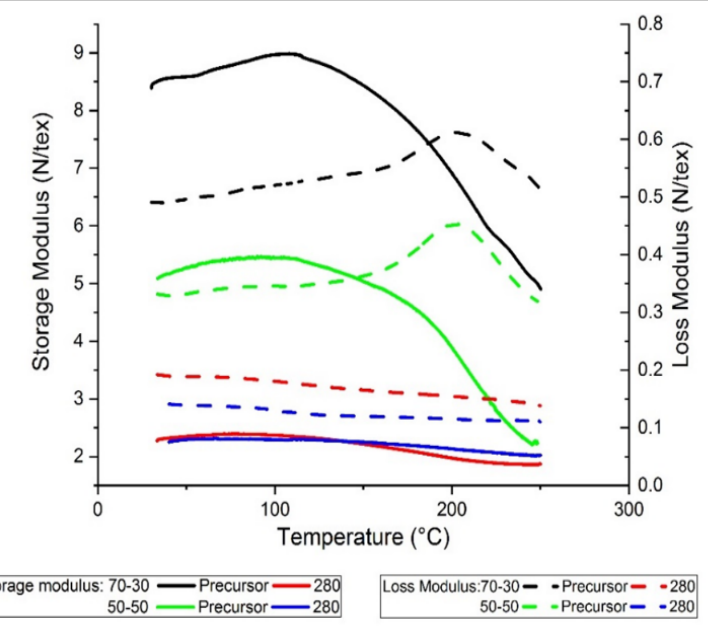

Figure 5: Temperature sweep of a) 70-30 stabilised fibre for different stabilisation temperatures; b) 70-30 stabilised fibre versus 50-50 stabilised fibres (both stabilised at $\left.280^{\circ} \mathrm{C}\right)$

\subsection{Morphology of the stabilised fibres}

Figure 6 shows the cross-section SEM images of 70-30 treated at different temperatures $\left(240^{\circ} \mathrm{C}, 260^{\circ} \mathrm{C}\right.$ and $\left.280^{\circ} \mathrm{C}\right)$ compared with the precursor fibres and the finishing treated fibres. The stabilised fibres have a smooth surface without any trace of skin-core formation which is common in PAN-based CFs (Frank et al. 2012; Nunna et al. 2016) and strongly impacts the mechanical properties of the final carbon fibres. However, filament fusion was observed at several points along the tow, which was not observed in the precursor fibres prior to stabilisation suggesting that fusion occurs during thermal treatment. When the precursors were stabilised in the oven, volatile compounds are released from thermal decomposition of precursors and are deposited on the surface of the filament causing filaments to fuse (Ford and Mitchell 1963). To solve this problem, a treatment with spin finish prior to stabilisation was used. Figure 6e shows the treated fibres after stabilisation, illustrating how a layer of spin finish covers the outside of the filaments preventing direct contact with each other.

In fibre production, the spin finish is normally used to improve the processability by improving the fibre-to-fibre interaction and reducing the fibre static electricity and friction. Moreover, the spin finish reduces the extent of filament breakage, so it has some advantageous 
effects on the mechanical properties of the precursors (Bajaj 1997; Ebeling et al. 2012; Garoff et al. 2016). However, the impact of spin finish on the conversion from precursor to carbon fibre has not been fully studied. While the application of spin finish can prevent fibre fusion during stabilisation, a thick layer may also inhibit the release of volatile compounds (Garoff et

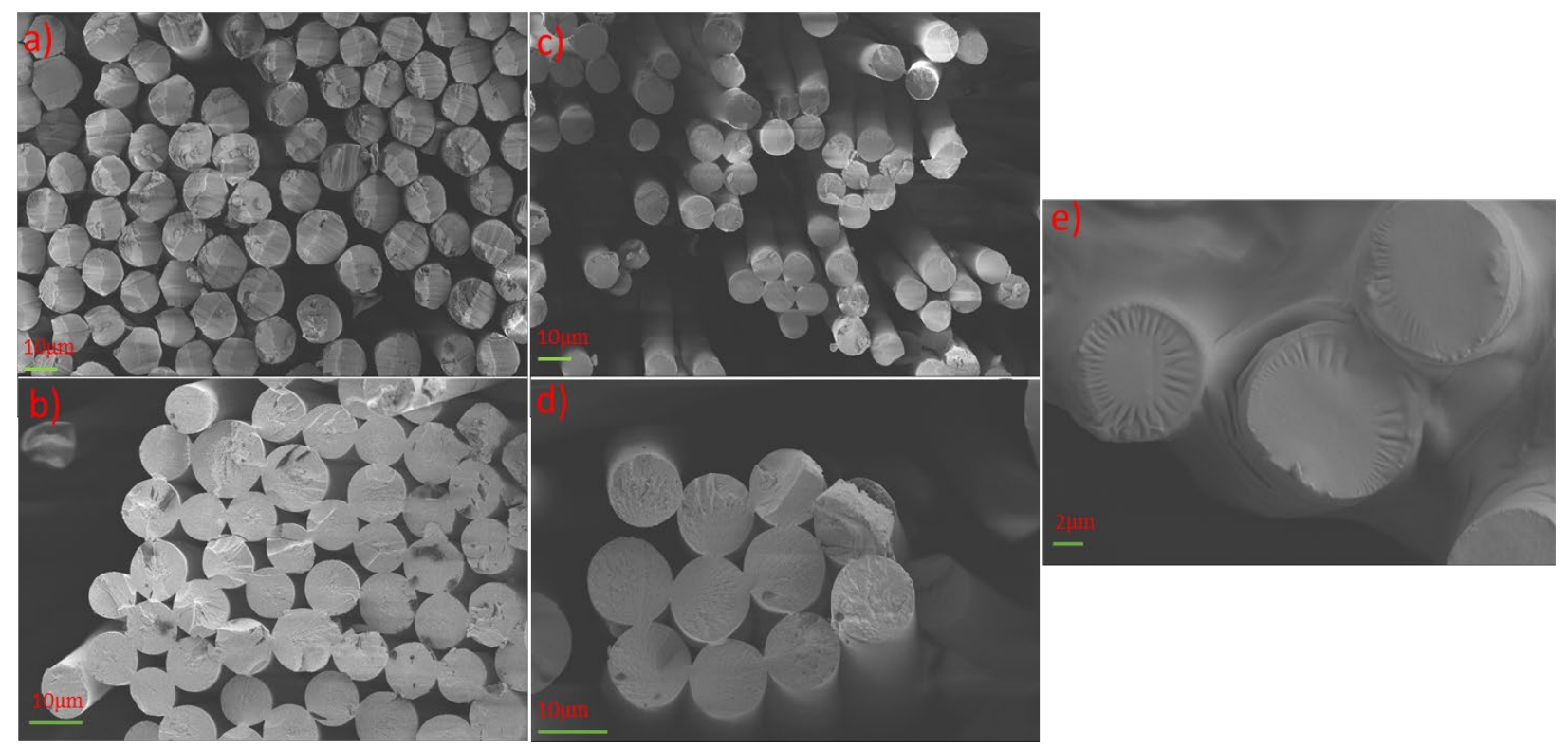

Figure 6: Cross section of a) unstabilised precursor, and stabilised fibres at b) $280^{\circ} \mathrm{C}$, c) $260^{\circ} \mathrm{C}$, d) $240^{\circ} \mathrm{C}$, e) $280^{\circ} \mathrm{C}$ stabilised fibres treated with spin finish al. 2016) which in turn could create voids in the fibre, despite increasing carbon yield. Moreover, its impact on the properties of the final carbon fibre needs to be fully considered. The application of a spin finish on carbon fibre production therefore will be investigated in a future study.

Another noticeable change is the shrinkage of the filament after stabilisation. The filament diameter reduces from 13-16 $\mu \mathrm{m}$ in the precursors to 8-11 $\mu \mathrm{m}$ in the stabilised fibres as a direct result of removing volatile compounds during stabilisation. This is common for all carbon fibres and in line with the TGA results presented above.

\section{Conclusions}

The effect of the temperature on the stabilisation process of the cellulose-lignin composite fibres has been studied here. Cellulose-lignin fibres with a different weight ratio (70-30 and 50-50) were stabilised at different temperature $\left(240{ }^{\circ} \mathrm{C}, 260{ }^{\circ} \mathrm{C}\right.$ and $\left.280^{\circ} \mathrm{C}\right)$ and revealed that stabilisation times decrease when the stabilisation temperature increased, while char yield decreased. It also found that the addition of lignin into the composite fibre increases the stabilisation time but decreases the char yield of the stabilisation process. However, the addition of lignin increases the carbon yield of the overall process. These findings open a new route to the development of low-cost CF production by increasing the overall carbon yield and potentially reduced production time. 
In terms of the fibre viscoelastic properties, it was found that the addition of lignin decreased the thermal resistance as well as the viscoelastic performance of the precursors. After stabilisation, fibres transformed from a thermoplastic-like behaviour to a thermoset-like one, resulting in no visible glass transition using DMA analysis. For this reason, DMA proved to be a promising tool to follow the stabilisation process of cellulose-lignin composite fibres. Moreover, the fusion of the precursors occurred during stabilisation, was prevented when a spin finish was applied.

\section{Conflicts of interest}

There are no conflicts to declare.

\section{Acknowledgements}

MT and MH have received funding from the European Research Council (ERC) under the European Union's Horizon 2020 research and innovation programme (grant agreement No 715788).

Bajaj P (1997) Spin finishes for manufactured fibres. In: Manufactured Fibre Technology. Springer, pp 139-169

Bajpai P (2017) Carbon Fibre from Lignin. Springer

Baker DA, Gallego NC, Baker FS (2012) On the characterization and spinning of an organicpurified lignin toward the manufacture of low-cost carbon fiber. J Appl Polym Sci 124:227234. https://doi.org/10.1002/app.33596

Bengtsson A, Bengtsson J, Sedin M, Sjöholm E (2019) Carbon Fibers from Lignin-Cellulose Precursors: Effect of Stabilization Conditions. ACS Sustain Chem Eng 7:8440-8448. https://doi.org/10.1021/acssuschemeng.9b00108

Bohner J, Weeber M, Kuebler F, Steinhilper R (2015) Developing a learning factory to increase resource efficiency in composite manufacturing processes BT - 5th Conference on Learning Factories 2015, July 7, 2015 - July 8, 2015. In: Elsevier. pp 64-69

Boukir A, Fellak S, Doumenq P (2019) Structural characterization of Argania spinosa Moroccan wooden artifacts during natural degradation progress using infrared spectroscopy (ATR-FTIR) and X-Ray diffraction (XRD). Heliyon 5:e02477. https://doi.org/10.1016/j.heliyon.2019.e02477 
Brodin I, Ernstsson M, Gellerstedt G, Sjöholm E (2012) Oxidative stabilisation of kraft lignin for carbon fibre production. Holzforschung 66:. https://doi.org/10.1515/HF.2011.133

Brunner PH, Roberts P V. (1980) The significance of heating rate on char yield and char properties in the pyrolysis of cellulose. Carbon N Y 18:217-224. https://doi.org/10.1016/00086223(80)90064-0

Byrne N, De Silva R, Ma Y, et al (2018) Enhanced stabilization of cellulose-lignin hybrid filaments for carbon fiber production. Cellulose 25:723-733. https://doi.org/10.1007/s10570-017-1579-0

Cho M, Karaaslan M, Chowdhury S, et al (2018) Skipping Oxidative Thermal Stabilization for Lignin-Based Carbon Nanofibers. ACS Sustain Chem Eng 6:6434-6444. https://doi.org/10.1021/acssuschemeng.8b00209

Choi D, Kil HS, Lee S (2019) Fabrication of low-cost carbon fibers using economical precursors and advanced processing technologies. Carbon N Y 142:610-649. https://doi.org/10.1016/j.carbon.2018.10.028

De Nardo L, Farè S (2017) Dynamico-mechanical characterization of polymer biomaterials. Charact Polym Biomater 203-232. https://doi.org/10.1016/B978-0-08-100737-2.00009-1

Ebeling H, Fink H-P, Lehmann A (2012) Method for the production of lignin-containing precursor fibres and also carbon fibres

Fang W, Yang S, Wang X-L, et al (2017) Manufacture and application of lignin-based carbon fibers (LCFs) and lignin-based carbon nanofibers (LCNFs). Green Chem 19:1794-1827. https://doi.org/10.1039/c6gc03206k

Ford CE, Mitchell C V. (1963) Fibrous graphite. US Pat. 3,107,152 1-5

Frank E, Hermanutz F, Buchmeiser MR (2012) Carbon fibers: Precursors, manufacturing, and properties. Macromol Mater Eng 297:493-501. https://doi.org/10.1002/mame.201100406

Frank E, Steudle LM, Ingildeev D, et al (2014) Carbon fibers: Precursor systems, processing, structure, and properties. Angew Chemie - Int Ed 53:5262-5298. https://doi.org/10.1002/anie.201306129

Garoff N, Protz R, Erdmann J, et al (2016) A process for the manufacture of a precursor yarn

Ghysels S, Ronsse F, Dickinson D, Prins W (2019) Production and characterization of slow pyrolysis biochar from lignin-rich digested stillage from lignocellulosic ethanol production. Biomass and Bioenergy 122:349-360. https://doi.org/10.1016/j.biombioe.2019.01.040 pure lignin carbon fibers through hardwood and herbaceous lignin blends. Int J Mol Sci 18:. 
Huang X (2009) Fabrication and Properties of Carbon Fibers. Materials (Basel) 2:2369-2403. https://doi.org/10.3390/ma2042369

Jiang W, Sun L, Hao A, Chen J (2011) Regenerated cellulose fibers from waste bagasse using ionic liquid. Text Res J 81:1949-1958. https://doi.org/10.1177/0040517511414974

Kadla JF, Kubo S, Venditti RA, et al (2002) Lignin-based carbon fibers for composite fiber applications. Carbon N Y 40:2913-2920. https://doi.org/10.1016/S0008-6223(02)00248-8

Kawamoto H (2017) Lignin pyrolysis reactions. J Wood Sci 63:117-132. https://doi.org/10.1007/s10086-016-1606-z

Kubo S, Kadla JF (2004) Poly(ethylene oxide)/organosolv lignin blends: Relationship between thermal properties, chemical structure, and blend behavior. Macromolecules 37:6904-6911. https://doi.org/10.1021/ma0490552

Kubo S, Kadla JF (2005) Kraft lignin/poly(ethylene oxide) blends: Effect of lignin structure on miscibility and hydrogen bonding. J Appl Polym Sci 98:1437-1444. https://doi.org/10.1002/app.22245

Lobo H, Bonilla J V. (2003) Handbook of Plastics Analysis. Marcel Dekker

Lu H, Cornell A, Alvarado F, et al (2016) Lignin as a Binder Material for Eco-Friendly Li-Ion Batteries. Materials (Basel) 9:127. https://doi.org/10.3390/ma9030127

Ma Y, Asaadi S, Johansson L-S, et al (2015) High-Strength Composite Fibers from Cellulose-Lignin Blends Regenerated from Ionic Liquid Solution. ChemSusChem 8:4030-4039. https://doi.org/10.1002/cssc.201501094

Mikkilä J, Trogen M, Koivu KAY, et al (2020) Fungal Treatment Modifies Kraft Lignin for LigninAnd Cellulose-Based Carbon Fiber Precursors. ACS Omega 5:6130-6140. https://doi.org/10.1021/acsomega.0c00142

Morgan P (2005) Carbon Fibers and Their Composites. CRC Press, Boca Raton

Nunna S, Naebe M, Hameed N, et al (2016) Investigation of progress of reactions and evolution of radial heterogeneity in the initial stage of thermal stabilization of PAN precursor fibres. Polym Degrad Stab 125:105-114. https://doi.org/10.1016/J.POLYMDEGRADSTAB.2016.01.008

Ogale AA, Zhang M, Jin J (2016) Recent advances in carbon fibers derived from biobased precursors. J Appl Polym Sci 133:. https://doi.org/10.1002/app.43794 
Olsson C, Sjöholm E, Reimann A (2017) Carbon fibres from precursors produced by dry-jet wetspinning of kraft lignin blended with kraft pulps. Holzforschung 71:275-283. https://doi.org/10.1515/hf-2016-0189

Shrivastava A (2018) Plastic Properties and Testing. In: Introduction to Plastics Engineering. Elsevier, pp 49-110

Sudo K, Shimizu K, Nakashima N, Yokoyama A (1993) A new modification method of exploded lignin for the preparation of a carbon fiber precursor. J Appl Polym Sci 48:1485-1491. https://doi.org/10.1002/app.1993.070480817

Tang M, Bacon R (1964) Carbonization of cellulose fibers-I. Low temperature pyrolysis. Carbon N Y 2:211-220. https://doi.org/10.1016/0008-6223(64)90035-1

Torregrosa MEM, Diez JC (2015) Reactions and Mechanisms in Thermal Analysis of Advanced Materials. Wiley Online Library

Trogen M, Le ND, Sawada D, et al (2021) Cellulose-lignin composite fibres as precursors for carbon fibres. Part 1 - Manufacturing and properties of precursor fibres. Carbohydr Polym 252:117133. https://doi.org/10.1016/j.carbpol.2020.117133

Uraki Y, Kubo S, Nigo N, et al (1995) Preparation of Carbon Fibers from Organosolv Lignin Obtained by Aqueous Acetic Acid Pulping. Holzforschung 49:343-350. https://doi.org/10.1515/hfsg.1995.49.4.343

Vincent S, Prado R, Kuzmina O, et al (2018) Regenerated Cellulose and Willow Lignin Blends as Potential Renewable Precursors for Carbon Fibers. ACS Sustain Chem \&amp; Eng 6:59035910. https://doi.org/10.1021/acssuschemeng.7b03200

Zhang M, Jin J, Ogale A (2015) Carbon Fibers from UV-Assisted Stabilization of Lignin-Based Precursors. Fibers 3:184-196. https://doi.org/10.3390/fib3020184 